\title{
Prevalence and correlates of poor sleep quality among college students: a cross- sectional survey
}

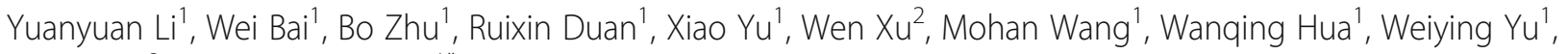
Wenjun $\mathrm{Li}^{2}$ and Changgui Kou ${ }^{1 *}$

\begin{abstract}
Background: Sleep problems are widespread among college students around the globe, especially in China. This study was designed to investigate the prevalence of poor sleep quality and identify associated factors among college students in Jilin Province, China.
\end{abstract}

Methods: A total of 6284 participants were completely collected by stratified cluster sampling in 2016. Information on basic demographics, lifestyles, social and family support, and subjective sleep quality was collected by questionnaire. The Pittsburgh Sleep Quality Index (PSQI) is a self-administered questionnaire used to assess sleep for one month.

Results: 1951 (31.0\%) participants were classified into poor sleep quality group, as defined by a PSQI score > 5 . Males scored significantly higher than females on sleep duration and use of sleep medication, while females scored significantly higher than males on PSQI total and sleep disturbances. The results of the multivariate logistic regression show the following factors to be significant predictors of poor sleep quality: freshman (OR $=1.523,95 \%$ Cl: 1.168-1.987), alcohol use (OR=1.634, 1.425-1.874), gambling behaviors ( $\mathrm{OR}=1.167,95 \% \mathrm{Cl}$ : 1.005-1.356), exercised for more than 30 min a week on less than one day ( $\mathrm{OR}=1.234,95 \% \mathrm{Cl}: 1.016-1.498)$, the feelings of satisfied with parental love $(\mathrm{OR}=1.849,95 \% \mathrm{Cl}: 1.244-2.749)$, and harmonious/neutral relationship with classmates $(\mathrm{OR}=2.206,95 \% \mathrm{Cl}: 1.312-3.708 ; \mathrm{OR}=1.700,95 \% \mathrm{Cl}: 1.414-2.045)$. No study pressure of this academic year $(\mathrm{OR}=$ $0.210,95 \% \mathrm{Cl}: 0.159-0.276)$, no truancy in the past month $(\mathrm{OR}=0.510,95 \% \mathrm{Cl}: 0.354-0.735)$, never had self-injurious behaviors ( $\mathrm{OR}=0.413,95 \% \mathrm{Cl}: 0.245-0.698)$, very harmonious family relationship ( $\mathrm{OR}=0.377,95 \% \mathrm{Cl}: 0.219-0.650)$, frequent communication with parents $(\mathrm{OR}=0.524,95 \% \mathrm{Cl}$ : $0.312-0.880)$, the feelings of satisfied with maternal love $(\mathrm{OR}=0.432,95 \% \mathrm{Cl}: 0.257-0.725)$, and frequent excursions to gymnasium $(\mathrm{OR}=0.770,95 \% \mathrm{Cl}: 0.659-0.899)$ were the protective factors.

Conclusions: The implication of the present study may be that college students must be made aware of the consequences of inadequate sleep quality and risk factors could be improved if students tried to change their behavior and subjective consciousness.

Keywords: Sleep quality, Adolescent, Adult, China

\footnotetext{
* Correspondence: koucg@jlu.edu.cn

'Department of Epidemiology and Biostatistics, School of Public Health, Jilin University, 1163 Xinmin Street, Changchun 130021, Jilin province, China

Full list of author information is available at the end of the article
}

C C The Author(s). 2020 Open Access This article is licensed under a Creative Commons Attribution 4.0 International License, which permits use, sharing, adaptation, distribution and reproduction in any medium or format, as long as you give appropriate credit to the original author(s) and the source, provide a link to the Creative Commons licence, and indicate if changes were made. The images or other third party material in this article are included in the article's Creative Commons. licence, unless indicated otherwise in a credit line to the material. If material is not included in the article's Creative Commons licence and your intended use is not permitted by statutory regulation or exceeds the permitted use, you will need to obtain permission directly from the copyright holder. To view a copy of this licence, visit http://creativecommons.org/licenses/by/4.0/ The Creative Commons Public Domain Dedication waiver (http://creativecommons.org/publicdomain/zero/1.0/) applies to the data made available in this article, unless otherwise stated in a credit line to the data. 


\section{Background}

Sleep is a pivotal modulator of neuroendocrine function, glucose regulation, and cardiovascular activity. The consequences of sufficient restorative sleep deprivation are severe, impacting human health, wellbeing, and functioning [1]. Poor sleep quality may have a negative impact on social, physical, and mental health, as well as the living quality of individuals. According to the cut-off (Pittsburgh Sleep Quality Index (PSQI) score > 5), a German community study indicated that the prevalence of poor sleep quality among people aged $18-80$ years was $36 \%$ [2]. In a cross-sectional study conducted in Hong Kong, China, the prevalence of poor sleep quality among 5001 adults was $39.4 \%$ [3].

As is well-known, college students in the transition period from home to college, from adolescence to adulthood are one of the most sleep-deprived age groups [4]. College students usually face numerous challenges, such as greater academic pressures, social obligations, internet distraction, being responsible for themselves, and erratic schedules. Carskadon and Davis [5] found that students entering the college had less sleep time and delayed sleep onset. Sleep problems can trigger negative health outcomes, such as mood disturbance, fatigue, impaired concentration, and poor academic performance. Sleep problems are widespread among college students around the globe, especially in China. Problems of poor sleep quality and lack of sleep are common among college students in Hong Kong [6]. Li et al. included 82,055 Chinese college students for meta-analysis, with an average sleep time of $7.08 \mathrm{~h} /$ day. The proportion of students who slept less than $6 \mathrm{~h} /$ day and $7 \mathrm{~h} /$ day (short sleep) was 8.4 and $43.9 \%$, respectively. The average bedtime is 12 : 51 a.m. The proportion of students with large sleep latency (time taken to fall asleep) of more than $30 \mathrm{~min}$ was $25.5 \%$ [7, 8]. Short sleep duration and unhealthy sleep patterns are common among Chinese university students [9]. Previous studies revealed that a considerable prevalence of poor sleep quality among this population ranged from 19.17 to $57.5 \%$ depending on the definition and measure used $[10,11]$.

Poor sleep quality is associated with a number of factors, including demographic characteristics, behavioral and lifestyle factors, physical activity, psychological factors, and chronic diseases. With age, sleep changes, such as shorter sleep time and increased sleep fragmentation [12]. Zhang et al. found that diseases and increased chronic diseases within 2 weeks in middle-aged and elderly patients were the main physiological health-related factors leading to poor sleep. Physical health may be a major determinant of sleep quality [13]. Wang et al. showed that advanced age, smoking, irregular diet, lack of physical exercise, poor mental health, chronic diseases, or multiple diseases were positively correlated with sleep deprivation [14]. Internet addiction is very prevalent in college students, particularly in Asian communities [15], and is closely associated with sleep problems [16]. In addition, poor sleep quality is also associated with stress levels and education levels [17].

Since the differences in social and cultural background between the East and the West cannot be neglected, the findings may not completely reflect the overall sleep characteristics of the Chinese population, including college students. Many studies on the prevalence of poor sleep quality and associated factors of college students were conducted in China, but other factors such as the family and social support have been overlooked, resulting in failing to obtain complete results.

The purpose of this study was to investigate the prevalence of poor sleep among college students in Jilin Province, China. We looked at factors that influence sleep quality, including demographics and lifestyle, as well as family and social support. Understanding these factors may help improve sleep quality, thereby promoting the development of strategies and raising the quality of life.

\section{Methods}

\section{Participants and sampling}

The study was carried out in 2016 in Jilin Province, China. The sample size was 7500 based on the reported prevalence of $30 \%$ poor sleep quality, a confidence level of $95 \%$, and an allowable error of 0.0001 . Before taking samples, the student roster of different majors and grades was collected, and the students who were absent from the school in the past one month due to their study, sickness and personal leave, and internship were excluded. All the universities included in the survey received permission from the university authorities. Respondents received oral notification of the study from the advisor and were informed that participation was optional. All respondents provided informed consent prior to participating in the study. The survey was conducted anonymously and no personal information was given. 7500 people from the selected sites were randomly selected and invited to participate in the study, accounting for about $1 \%$ of the total number of college students in Jilin province. The overall response rate as $95.8 \%$ (313 participants refused to respond). The sampling of the survey was conducted by Jilin University using a stratified cluster sampling method. The detailed process of the sampling process was shown in Fig. 1. After the questionnaires were collected, 903 unqualified questionnaires were deleted, 6284 questionnaires included in the final analysis. Multiple imputation was used to deal with missing data for the PSQI scale. Frequency interpolation was used to deal with missing data for ranked data. Mean interpolation and mode interpolation were used to process the missing data in quantitative data of central 


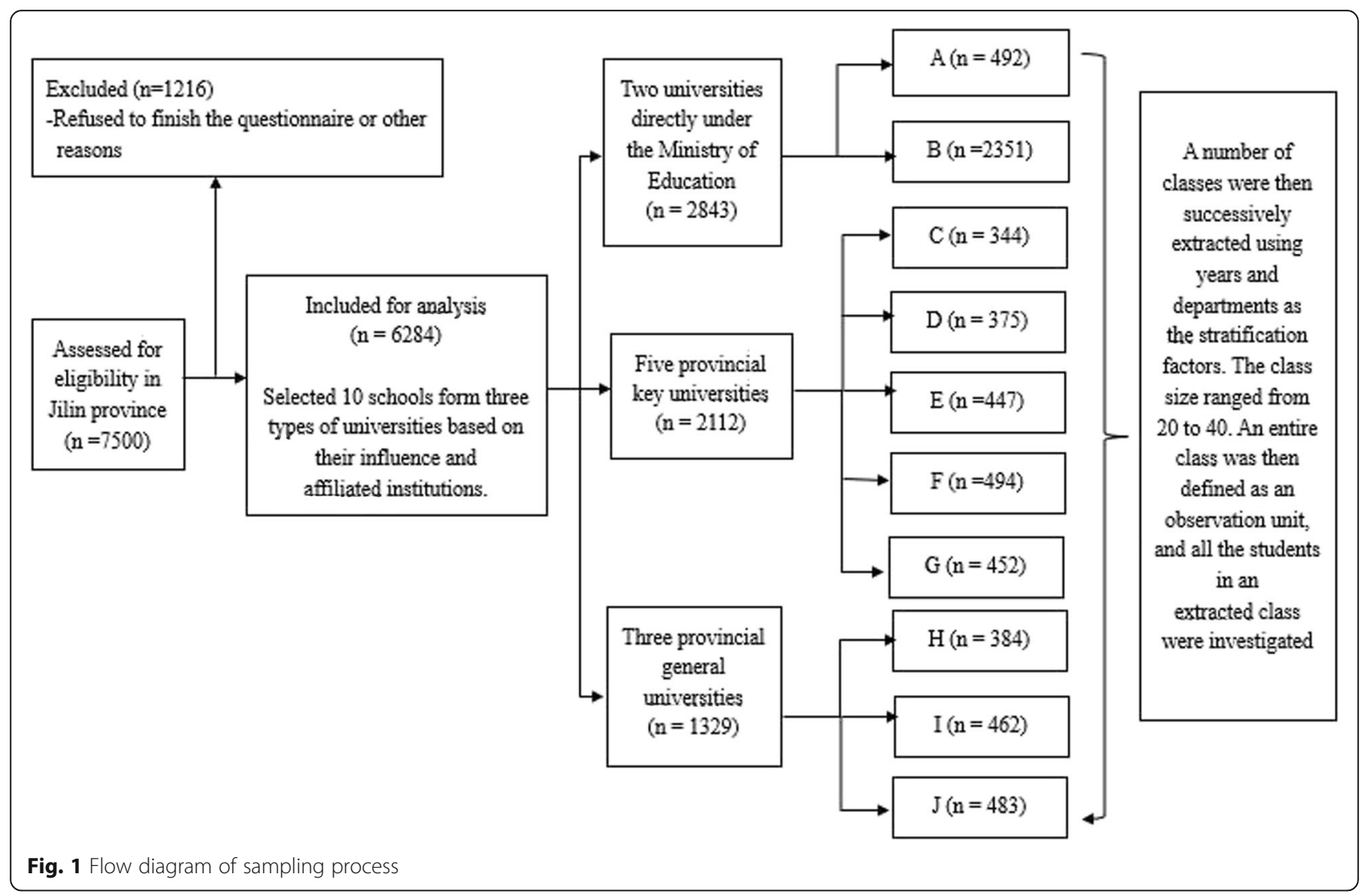

tendency and discrete tendency, respectively. The study protocol was approved by the Survey and Behavioral Ethics Committee of the School of Public Health, Jilin University.

\section{Data and collection}

PSQI is a self-administered questionnaire used to assess sleep for one month. The index consists of 19 items grouped into 7 components (subjective sleep quality, sleep latency, sleep duration, sleep efficiency, sleep disturbance, daytime dysfunction, and frequency of sleep medications) with 0 (no difficulty) to 3 (severe difficulty). The sum of these 7 components is a global score (range $0-21)$. The lower the score, the better the quality of sleep. The total score of PSQI $>5$ indicates poor sleep quality with a sensitivity of $89.6 \%$ and specificity of 86.5\% [18]. The Chinese version of PSQI has been widely used in the evaluation of sleep in other regions of China, with good reliability and validity [19].

Information on basic demographic characteristics, lifestyles, social and family support, and subjective sleep quality was collected using a self-report questionnaire. The basic demographic characteristics included age, gender, ethnicity, grade, body mass index (BMI), monthly family per capita income, and monthly living cost. BMI was calculated using self-reported height and weight as weight in $\mathrm{kg}$ divided by height in meters squared [20, 21]. Lifestyle factors included tobacco and alcohol use, study pressure during the school year, days off from school, self-injurious behaviors, suicidal ideation in the past 12 months, gambling, and exercise. Tobacco use (at least one cigarette a day a week), alcohol use (one glass of an alcoholic drink, such as half bottle/can of beer, one glass of Chinese liquor, one glass of wine or rice wine) and gambling were categorized into "yes" or "no". Study pressure was measured by "How about your study pressure and burden this academic year?". Days off from school was measured by "In the past 30 days, how many days have you missed classes without asking for leave?". Self-injurious behaviors were measured by "In the past 12 months, have you intentionally hurt yourself (burning a cigarette, cutting with a razor blade, banging your head against a wall, etc.)?". Suicidal ideation was measured by "Have you had suicidal ideation in the past 12 months?". Exercise intensity was identified by asking "how many days per week do you exercise for more than 30 minutes at a time?". Family support is made up of five questions: "How do you feel about your family relationship?", "What is your parents' marital status and relationship?", "How often do you communicate with your parents?", "How satisfied you are with your father's love?", "How satisfied you are with your mother's love?". Social 
support was measured with four questions, "How do you feel about your relationship with your classmates?", "How many close friends do you have?", "Where do you often go with your friends?", "Do you have a boyfriend/ girlfriend?" Social and family support was ascertained by asking students to self-evaluate their relationships and satisfaction with parents, classmates, or friends on a fivepoint scale from very harmonious/satisfaction to highly disharmonious/dissatisfied.

\section{Statistical analysis}

Statistical analyses were performed by SPSS 24.0 (Statistical Product and Service Solutions Inc., Chicago, IL, USA). Basic socio-demographic characteristics, lifestyles, and social and family support were also compared between good and poor sleep quality using univariate logistic analyses for categorical variables. The gender differences for the seven PSQI components were analyzed via t-test. Multi-collinearity diagnosis was conducted for variables with statistical significance. Variables with variance inflation factor (VIF) $<3$ were included in the multivariate analysis. If there is a collinearity problem, principal component analysis and factor analysis are used to extract common factors and carry out multivariate logistic regression analysis of preselected variables. The multivariate logistic regression was used to obtain odds ratios (OR) and 95\% confidence intervals $(\mathrm{CI})$ of predictors, and explore the association between factors and sleep quality. Wald test was used to test the hypothesis of the regression coefficient. Twotailed $p<0.05$ was applied to determine the statistical significance.

\section{Results}

A total of 6284 eligible questionnaires from undergraduate university student participants were completed in the study. The sample included $52.7 \%$ male and $47.3 \%$ female. The age of the students ranged from 15 to 25 years, and the mean age was 19.76 years $(S D=1.45)$. The number of students $\leq 20$ years old and $>20$ years old was 4550 and 1734 respectively. There were 2586 freshmen, 1966 sophomores, 1072 juniors, and 660 senior and senior five.

Table 1 shows the basic demographic differences between students with poor and good sleep quality. There were $4233(69.0 \%)$ and 1951 (31.0\%) with good and poor sleep quality, respectively. The difference in age groups and BMI was non-significant between subjects with good and poor sleep quality (. Students in lower grades had a higher prevalence of poor sleep quality than students in higher grades $(p<0.05)$.

Table 2 provides for differences in lifestyle factors and subgroups with good or poor sleep quality. Among students who drank alcohol $(\mathrm{p}<0.001)$, had higher academic pressure $(\mathrm{p}<0.001)$, more days of school absenteeism ( $\mathrm{p}<$ $0.001)$, had often self-injurious behaviors $(\mathrm{p}<0.05)$, gambled $(\mathrm{p}<0.05)$, and regularly exercised less than one day a week $(p<0.05)$, there was a higher prevalence of poor sleep quality.

Table 3 shows the family and social support and subgroups with good or poor sleep quality and reveals that students who lacked communication with parents $(\mathrm{p}<$ $0.05)$, were dissatisfied with their parental love $(p<0.05)$, and had disharmonious family relationships $(\mathrm{p}<0.05)$, were significantly more likely to be poor sleepers. As for social support related factors, often go to Bar/Karaoke hall/Song and dance hall with friends $(\mathrm{p}<0.05)$ were also significantly associated with poor sleep quality.

Collinearity diagnosis was conducted for variables with a statistically significant difference in univariate logistic regression analysis, and variables with $\mathrm{VIF}<3$ were included in the multivariable logistic regression (Table 4).

The results of the multivariable logistic regression show that students in the lower grades had an increased risk of poor sleep quality $(p<0.05)$. Specifically, freshman and sophomore had a higher risk compared with that senior and senior five $(\mathrm{OR}=1.523,95 \% \mathrm{CI}: 1.168-1.987$; $\mathrm{OR}=1.327,95 \% \mathrm{CI}$; 1.030-1.709). Alcohol use $(\mathrm{OR}=$ $1.634,1.425-1.874)$ was significantly associated with poor sleep quality $(p<0.05)$. Gambling behaviors $(\mathrm{OR}=$ 1.167, 95\% CI: $1.005-1.356)$ was also shown to be a risk factor $(p<0.05)$. Students who exercised for more than 30 min a week on less than one day $(\mathrm{OR}=1.234,95 \% \mathrm{CI}$ : 1.016-1.498) had a higher risk of poor sleep quality than those who exercised for 5 to 7 days a week). Feelings of satisfied with parental $(\mathrm{OR}=1.849,95 \%$ CI: $1.244-$ 2.749), and harmonious/neutral relationship with classmates $(\mathrm{OR}=2.206,95 \% \mathrm{CI}: 1.312-3.708 ; \mathrm{OR}=1.700$, 95\% CI: 1.414-2.045) were also risk factors $(p<0.05)$. Students with study pressure of this academic year had an increased risk during poor sleep quality $(p<0.001)$. Students with no study pressure $(\mathrm{OR}=0.210,95 \% \mathrm{CI}$ : 0.159-0.276) and had the lowest sleep risk than those with great study pressure. Students who did not skip school $(\mathrm{OR}=0.510,95 \% \mathrm{CI}$ : $0.354-0.735)$ had a lower risk of poor sleep quality than those who stayed away from school for more than 5 days in the past month. A lower risk was also found for students who never $(\mathrm{OR}=$ 0.413 , 95\% CI: $0.245-0.698)$ and sometimes $(\mathrm{OR}=0.372$, 95\% CI: $0.180-0.769$ ) had self-injurious behaviors compared to students who often self-injurious behaviors.

In comparison with highly disharmonious family relationships, very harmonious (OR $=0.377,95 \% \mathrm{CI}$ : 0.219 0.650 ), harmonious $(\mathrm{OR}=0.473,95 \% \mathrm{CI}: 0.274-0.817$ ) and neutral family relationships $(\mathrm{OR}=0.498,95 \% \mathrm{CI}$ : $0.282-0.879$ ) had a lower risk of poor sleep quality. Frequent communication with parents $(\mathrm{OR}=0.524,95 \% \mathrm{CI}$ : $0.312-0.880$ ), the feelings of satisfied with maternal love 
Table 1 Basic demographic characteristics and sleep quality

\begin{tabular}{|c|c|c|c|c|c|c|c|}
\hline Variables & Total $(n=6284)$ & $\mathrm{Cr}$ & Good sleep quality $(n=4233)$ & Poor sleep quality $(n=1951)$ & OR & $95 \% \mathrm{Cl}$ & $p$ \\
\hline \multicolumn{8}{|l|}{ Age } \\
\hline$\leq 20$ & 4550 & $72.4 \%$ & $3106(68.3)$ & $1444(31.7)$ & 1.000 & & \\
\hline$>20$ & 1734 & $27.6 \%$ & 1227(70.8) & $507(29.2)$ & 1.044 & $0.871-1.252$ & 0.638 \\
\hline \multicolumn{8}{|l|}{ Gender } \\
\hline Male & 3310 & $52.7 \%$ & $2284(69.0)$ & 1026(31.0) & 1.000 & & \\
\hline Female & 2974 & $47.3 \%$ & 2049(68.9) & $925(31.1)$ & 1.017 & $0.888-1.166$ & 0.804 \\
\hline \multicolumn{8}{|l|}{ Ethnicity } \\
\hline Han & 5737 & $91.3 \%$ & $3955(68.9)$ & 1782(31.1) & 1.000 & & \\
\hline Minority & 547 & $8.7 \%$ & $378(69.1)$ & 169(30.9) & 0.999 & $0.815-1.225$ & 0.993 \\
\hline \multicolumn{8}{|l|}{ BMI $\left(\mathrm{kg} / \mathrm{m}^{2}\right)$} \\
\hline$<18.5$ & 1158 & $18.5 \%$ & $813(70.2)$ & $345(29.8)$ & 1.000 & & 0.228 \\
\hline $18.5-23.9$ & 4054 & $64.5 \%$ & $2785(68.7)$ & 1269(31.3) & 0.769 & $0.588-1.005$ & 0.055 \\
\hline $24-27.9$ & 774 & $12.3 \%$ & $543(70.2)$ & $231(29.8)$ & 0.825 & $0.645-1.056$ & 0.127 \\
\hline$\geq 28$ & 298 & $4.7 \%$ & $192(64.4)$ & 106(35.6) & 0.771 & $0.581-1.022$ & 0.071 \\
\hline \multicolumn{8}{|l|}{ Grade } \\
\hline Freshman & 2586 & $41.2 \%$ & 1755(67.9) & $831(32.1)$ & 1.000 & & 0.002 \\
\hline Sophomore & 1966 & $31.3 \%$ & $1337(68.0)$ & $629(32.0)$ & 0.873 & $0.760-1.002$ & 0.054 \\
\hline Junior & 1072 & $17.0 \%$ & 759(70.8) & $313(29.2)$ & 0.677 & $0.550-0.834$ & $<0.001$ \\
\hline Senior and se & & $10.5 \%$ & $482(73.0)$ & 178(27.0) & 0.663 & $0.508-0.866$ & 0.003 \\
\hline \multicolumn{8}{|c|}{ Monthly family income per capita ( $¥)$} \\
\hline$<3000$ & 2909 & $46.3 \%$ & 1974(67.9) & 1974(32.1) & 1.000 & & 0.901 \\
\hline $3000-4999$ & 1916 & $30.5 \%$ & 1343(70.1) & 1343(29.9) & 1.029 & $0.891-1.188$ & 0.695 \\
\hline 5000-6999 & 842 & $13.4 \%$ & $589(70.0)$ & $589(30.0)$ & 1.005 & $0.830-1.217$ & 0.961 \\
\hline$\geq 7000$ & 617 & $9.8 \%$ & $427(69.2)$ & $427(30.8)$ & 1.085 & $0.864-1.362$ & 0.481 \\
\hline \multicolumn{8}{|c|}{ Monthly living expenses (¥) } \\
\hline$<1000$ & 2036 & $32.4 \%$ & $1367(67.1)$ & $669(32.9)$ & 1.000 & & 0.087 \\
\hline $1000-2000$ & 3646 & $58.0 \%$ & 2537(69.6) & $1109(30.4)$ & 0.874 & $0.762-1.004$ & 0.057 \\
\hline $2001-3000$ & 467 & $7.4 \%$ & $338(72.4)$ & 129(27.6) & 0.829 & $0.636-1.082$ & 0.168 \\
\hline$>3000$ & 135 & $2.1 \%$ & $91(67.4)$ & $44(32.6)$ & 1.245 & $0.796-1.947$ & 0.336 \\
\hline
\end{tabular}

Note: $\mathrm{Cr}$, Constituent ratio; $¥ 1000=\$ 141$

$(\mathrm{OR}=0.432$, 95\% CI: $0.257-0.725)$ and often went to the gymnasium $(\mathrm{OR}=0.770,95 \% \mathrm{CI}$ : 0.659-0.899) were the protective factors of poor sleep quality (Table 5).

Differences between the genders for the seven PSQI components are depicted in Appendix 2. The mean sleep quality score was $4.51(S D=2.52)$, the median sleep latency was $10.0 \mathrm{~min}$ (P25-P75, 5.0-20.0), the mean sleep efficiency was $96.21 \%(S D=3.85)$, the mean sleep duration was $7.47 \mathrm{~h}(S D=1.15)$, and of them, 1.97, 9.01, 29.46 , and $59.56 \%$ were in $<5 / 5-/ 6-/\rangle 7$ (h) sleep duration subgroups, respectively. Table 5 shows that males scored significantly higher than females on sleep duration $(p=0.012)$ and use of sleep medication $(p=0.013)$, while females scored significantly higher than males on PSQI total $(p=0.041)$ and sleep disturbances $(p<0.001)$. No significant difference was observed in subjective sleep quality, sleep latency, sleep efficiency, and daytime dysfunction between males and females.

\section{Discussion}

The present study explored the prevalence and associated factors of poor sleep quality among college students in Jilin province, China. With the cut-off (PSQI > 5), our findings of the PSQI total mean score of $4.51(S D=2.52)$ and the $31.0 \%$ prevalence of poor sleep quality were similar to those found in a study conducted in Taiwan university students [22], who had the PSQI total mean score of $4.9(S D=2.4)$ and a $33.8 \%$ prevalence of poor sleep quality. Furthermore, our result is lower than the prevalence of poor sleep quality in a general university sample in Ethiopia (55.8\%) [23] and in Hong Kong 
Table 2 Univariate logistic regression analysis of lifestyle factors with sleep quality

\begin{tabular}{|c|c|c|c|c|c|c|c|}
\hline Variables & Total & $\mathrm{Cr}$ & Good sleep quality n(\%) & Poor sleep quality n(\%) & OR & $95 \% \mathrm{Cl}$ & $p$ \\
\hline \multicolumn{8}{|l|}{ Tobacco use } \\
\hline yes & 354 & $5.6 \%$ & $232(65.5)$ & $122(34.5)$ & 1.000 & & \\
\hline no & 5930 & $94.4 \%$ & $4101(69.2)$ & 1829(30.8) & 0.927 & $0.716-1.200$ & 0.564 \\
\hline \multicolumn{8}{|l|}{ Alcohol use } \\
\hline yes & 4394 & $69.9 \%$ & $2880(65.5)$ & $1514(34.5)$ & 1.000 & & \\
\hline no & 1890 & $30.1 \%$ & 1453(76.9) & $437(23.1)$ & 0.607 & $0.528-0.697$ & $<0.001$ \\
\hline \multicolumn{8}{|c|}{ Study pressure of this academic year } \\
\hline no & 887 & $14.1 \%$ & $733(82.6)$ & 154(17.4) & 1.000 & & $<0.001$ \\
\hline smaller & 903 & $14.4 \%$ & $676(74.9)$ & $227(25.1)$ & 1.381 & $1.082-1.762$ & 0.009 \\
\hline general & 2611 & $41.5 \%$ & 1894(72.5) & $717(27.5)$ & 1.535 & $1.245-1.893$ & $<0.001$ \\
\hline larger & 1488 & $23.7 \%$ & $846(56.9)$ & $642(43.1)$ & 3.032 & $2.437-3.772$ & $<0.001$ \\
\hline great & 395 & $6.3 \%$ & 184(46.6) & $211(53.4)$ & 4.848 & $3.672-6.401$ & $<0.001$ \\
\hline \multicolumn{7}{|c|}{ Days off from school(/month) } & $<0.001$ \\
\hline 0 & 5049 & $80.3 \%$ & $3591(71.1)$ & 1458(28.9) & 1.000 & & $<0.001$ \\
\hline$<1$ & 574 & $9.1 \%$ & $348(60.6)$ & $226(39.4)$ & 1.587 & $1.307-1.926$ & $<0.001$ \\
\hline $1-2$ & 395 & $6.3 \%$ & 260(65.8) & $135(34.2)$ & 1.371 & $1.067-1.762$ & 0.014 \\
\hline $3-4$ & 110 & $1.8 \%$ & $57(51.8)$ & $53(48.2)$ & 2.076 & $1.366-3.157$ & $<0.001$ \\
\hline$\geq 5$ & 156 & $2.5 \%$ & $77(49.4)$ & 79(50.6) & 1.914 & $1.326-2.764$ & $<0.001$ \\
\hline \multicolumn{8}{|c|}{ Self-injurious behaviors } \\
\hline never & 5929 & $94.4 \%$ & $4134(69.7)$ & 1795(30.3) & 1.000 & & 0.002 \\
\hline Occasionally & 196 & $3.1 \%$ & 106(54.1) & $90(45.9)$ & 1.575 & $1.141-2.175$ & 0.006 \\
\hline sometimes & 75 & $1.2 \%$ & $52(69.3)$ & 23(30.7) & 0.798 & $0.444-1.435$ & 0.452 \\
\hline often & 84 & $1.3 \%$ & $41(48.8)$ & $43(51.2)$ & 2.018 & $1.165-3.495$ & 0.012 \\
\hline \multicolumn{8}{|c|}{ Suicidal ideation in the past 12 months } \\
\hline yes & 576 & $9.20 \%$ & $338(58.7)$ & 238(41.3) & 1.219 & $0.989-1.503$ & 0.064 \\
\hline no & 5708 & $90.80 \%$ & 3995(70.0) & 1713(30.0) & 1.000 & & \\
\hline \multicolumn{8}{|c|}{ Gambling behaviors } \\
\hline yes & 1137 & $18.1 \%$ & $734(64.6)$ & 403(35.4) & 1.000 & & \\
\hline no & 5147 & $81.9 \%$ & 3599(69.9) & 1548(30.1) & 0.852 & $0.732-0.990$ & 0.037 \\
\hline \multicolumn{8}{|c|}{ Exercise for more than $30 \mathrm{~min}$ (days/week) } \\
\hline 0 & 1526 & $24.3 \%$ & $961(63)$ & $565(37)$ & 1.000 & & 0.002 \\
\hline $1-2$ & 2687 & $42.8 \%$ & 1893(70.5) & $794(29.5)$ & 0.768 & $0.663-0.888$ & $<0.001$ \\
\hline $3-4$ & 1128 & $18.0 \%$ & $807(71.5)$ & $321(28.5)$ & 0.737 & $0.612-0.886$ & 0.001 \\
\hline $5-7$ & 943 & $15.0 \%$ & $672(71.3)$ & $271(28.7)$ & 0.822 & $0.676-0.999$ & 0.049 \\
\hline
\end{tabular}

Note: $\mathrm{Cr}$, Constituent ratio; $P$ is for $\mathrm{OR}$

(57.5\%) [10], but higher than another study of medical students in China (19.2\%) [11].

Based on the basic demographic results, students in lower grades had a higher prevalence of poor sleep quality compared with those in the higher grades. Freshmen might be more susceptible to the new freedoms of living away from home for the first time and have little experience in dealing with the academic rigor of the curriculum. Similar results were found in the previous study [24]. No significant differences were found between males and females in the prevalence of poor sleep quality; this seems to contradict other previous reports $[3,25]$. We also found no association between sleep quality and BMI in college students, while other studies reported sleep quality had a significant association with BMI in the general population $[26,27]$. Ethnicity, age structure, region, socioeconomic level, and lifestyle might be partly responsible for the differences $[13,26,28,29]$. 
Table 3 Univariate logistic regression analysis of family and social support with sleep quality

\begin{tabular}{|c|c|c|c|c|c|c|c|}
\hline \multirow{2}{*}{$\begin{array}{l}\text { Variables } \\
\text { Family relationship }\end{array}$} & \multicolumn{2}{|l|}{ Total } & \multirow[t]{2}{*}{ Good sleep quality n(\%) } & \multirow[t]{2}{*}{ Poor sleep quality n(\%) } & \multirow[t]{2}{*}{ OR } & \multirow[t]{2}{*}{$95 \% \mathrm{Cl}$} & \multirow[t]{2}{*}{$p$} \\
\hline & & & & & & & \\
\hline Very harmonious & 3884 & $61.8 \%$ & $2870(73.9)$ & 1014(26.1) & 1.000 & & $<0.001$ \\
\hline Harmonious & 1822 & $29.0 \%$ & $1142(62.7)$ & $680(37.3)$ & 1.260 & $1.088-1.459$ & 0.002 \\
\hline Neutral & 442 & $7.0 \%$ & $262(59.3)$ & 180(40.7) & 1.270 & $0.980-1.647$ & 0.071 \\
\hline Disharmonious & 69 & $1.1 \%$ & $31(44.9)$ & $38(55.1)$ & 2.026 & $1.166-3.522$ & 0.012 \\
\hline Highly disharmonious & 67 & $1.1 \%$ & $28(41.8)$ & $39(58.2)$ & 2.395 & $1.356-4.228$ & 0.003 \\
\hline \multicolumn{8}{|l|}{ Parental marital status } \\
\hline Harmonious & 5402 & $86.0 \%$ & $3805(70.4)$ & 1597(29.6) & 1.000 & & 0.847 \\
\hline Frequent quarrel & 494 & $7.9 \%$ & 295(59.7) & 199(40.3) & 0.984 & $0.778-1.244$ & 0.893 \\
\hline Separation & 79 & $1.3 \%$ & $46(58.2)$ & $33(41.8)$ & 1.204 & $0.724-2.001$ & 0.475 \\
\hline Divorce & 309 & $4.9 \%$ & $187(60.5)$ & $122(39.5)$ & 1.073 & $0.814-1.415$ & 0.617 \\
\hline \multicolumn{8}{|l|}{ Communication with parents } \\
\hline Substantial & 1567 & $24.9 \%$ & $1186(75.7)$ & $381(24.3)$ & 1.000 & & $<0.001$ \\
\hline Often & 2290 & $36.4 \%$ & 1594(69.6) & $696(30.4)$ & 1.777 & $1.025-3.079$ & 0.040 \\
\hline Neutral & 1857 & $29.6 \%$ & $1162(62.6)$ & 695(37.4) & 2.511 & $1.486-4.242$ & $<0.001$ \\
\hline Rarely & 398 & $6.3 \%$ & 253(63.6) & 145(36.4) & 2.172 & $1.285-3.671$ & 0.004 \\
\hline Never & 172 & $2.7 \%$ & 138(80.2) & $34(19.8)$ & 1.997 & $1.179-3.383$ & 0.010 \\
\hline \multicolumn{8}{|l|}{ Satisfaction with paternal love } \\
\hline Very satisfied & 3091 & $49.2 \%$ & $2252(72.9)$ & $839(27.1)$ & 1.000 & & 0.026 \\
\hline Satisfied & 2019 & $32.1 \%$ & $1362(67.5)$ & $657(32.5)$ & 1.288 & $0.756-2.197$ & 0.352 \\
\hline Neutral & 786 & $12.5 \%$ & $471(59.9)$ & $315(40.1)$ & 0.795 & $0.500-1.265$ & 0.333 \\
\hline Dissatisfied & 174 & $2.8 \%$ & $94(54.0)$ & $80(46.0)$ & 0.687 & $0.437-1.081$ & 0.104 \\
\hline Very dissatisfied & 214 & $3.4 \%$ & 154(72.0) & $60(28.0)$ & 0.702 & $0.446-1.103$ & 0.125 \\
\hline \multicolumn{8}{|l|}{ Satisfaction with maternal love } \\
\hline Very satisfied & 3750 & $59.7 \%$ & $2677(71.4)$ & 1073(28.6) & 1.000 & & 0.011 \\
\hline Satisfied & 1855 & $29.5 \%$ & $1215(65.5)$ & $640(34.5)$ & 0.698 & $0.352-1.384$ & 0.304 \\
\hline Neutral & 397 & $6.3 \%$ & $236(59.4)$ & 161(40.6) & 1.553 & $0.868-2.780$ & 0.138 \\
\hline Dissatisfied & 113 & $1.8 \%$ & $77(68.1)$ & $36(31.9)$ & 1.688 & $0.976-2.919$ & 0.061 \\
\hline Very dissatisfied & 169 & $2.7 \%$ & 128(75.7) & $41(24.3)$ & 1.652 & $0.957-2.852$ & 0.072 \\
\hline \multicolumn{8}{|l|}{ Relationship with classmates } \\
\hline Very harmonious & 1791 & $28.5 \%$ & $1371(76.5)$ & $420(23.5)$ & 1.000 & & $<0.001$ \\
\hline Harmonious & 3164 & $50.4 \%$ & $2191(69.2)$ & 973(30.8) & 1.696 & $0.762-3.772$ & 0.196 \\
\hline Neutral & 1157 & $18.4 \%$ & $659(57.0)$ & 498(43.0) & 1.308 & $0.664-2.578$ & 0.438 \\
\hline Disharmonious & 80 & $1.3 \%$ & $45(56.3)$ & $35(43.8)$ & 0.878 & $0.446-1.732$ & 0.708 \\
\hline Highly disharmonious & 92 & $1.5 \%$ & $67(72.8)$ & $25(27.2)$ & 0.785 & $0.398-1.550$ & 0.486 \\
\hline \multicolumn{8}{|l|}{ Number of good friends } \\
\hline None & 147 & $2.3 \%$ & $91(61.9)$ & $56(38.1)$ & 1.000 & & 0.415 \\
\hline One & 233 & $3.7 \%$ & $150(64.4)$ & 83(35.6) & 0.694 & $0.413-1.168$ & 0.169 \\
\hline Two & 826 & $13.1 \%$ & $524(63.4)$ & 302(36.6) & 0.793 & $0.496-1.268$ & 0.332 \\
\hline Three and above & 5078 & $80.8 \%$ & $3568(70.3)$ & $1510(29.7)$ & 0.730 & $0.464-1.149$ & 0.174 \\
\hline \multicolumn{8}{|l|}{ Places often going with friends } \\
\hline Gymnasium & 1662 & $26.40 \%$ & $1258(75.7)$ & $404(24.3)$ & 1.000 & & 0.002 \\
\hline Bar/Karaoke hall/Song and dance hall & 809 & $12.90 \%$ & $509(62.9)$ & $300(37.1)$ & 1.391 & $1.137-1.702$ & 0.001 \\
\hline Billiard hall & 301 & $4.80 \%$ & 216(71.8) & $85(28.2)$ & 0.996 & $0.740-1.341$ & 0.979 \\
\hline
\end{tabular}


Table 3 Univariate logistic regression analysis of family and social support with sleep quality (Continued)

\begin{tabular}{|c|c|c|c|c|c|c|c|}
\hline Variables & Total & & Good sleep quality n(\%) & Poor sleep quality n(\%) & OR & $95 \% \mathrm{Cl}$ & p \\
\hline Internet cafes & 630 & $10.00 \%$ & 449(71.3) & $181(28.7)$ & 1.020 & $0.814-1.278$ & 0.861 \\
\hline Other & 2882 & $45.90 \%$ & $1901(66.0)$ & $981(34.0)$ & 1.286 & $1.101-1.503$ & 0.002 \\
\hline \multicolumn{8}{|c|}{ boyfriend or girlfriend } \\
\hline Yes & 1587 & $25.3 \%$ & 1125(70.9) & $462(29.1)$ & 1.000 & & \\
\hline No & 4697 & $74.7 \%$ & $3208(68.3)$ & 1489(31.7) & 1.142 & $0.997-1.308$ & 0.056 \\
\hline
\end{tabular}

Note: $\mathrm{Cr}$, Constituent ratio; $P$ is for $\mathrm{OR}$

Regarding lifestyle, in the present study poor sleep quality was found to be associated with alcohol use, study pressure, days off from school, self-injurious behaviors, suicidal ideation, gambling, and physical exercise. Smoking is considered as a negative factor for improving sleep quality [30], but this was not observed in our study.

This work also found that poor sleep quality was associated with family and social support. A study demonstrated that family and social support may be an important determinant of sleep quality in the elderly [30, 31]. Daytime emotional stress, which may be disrupted by the interpersonal environment, has a strong relationship with sleep quality [32]. Therefore, this study found the association between social support and sleep quality is reasonable.

Our multiple logistic regression results also showed that lower grade, disharmonious family relationships, less frequent communication with parents, alcohol use, study pressure, more days of school absenteeism, selfinjurious, suicidal ideation, and physical exercise more often could increase the odds of poor sleep quality after controlling gender and age.

The sleep quality of female students was not worse than that of male students in terms of global PSQI scores and sleep disturbances. The only two significant gender findings were that male students had worse sleep quality in terms of sleep duration and use of sleep medication relative to female students.

Nevertheless, there existed some limitations. First, due to the cross-sectional design of this study, the causal relationship between sleep quality and factors could not be determined; further multi-center and longitudinal studies need to be done. Second, the study only covered college students in just Jilin Province, so the results may not necessarily be generalized to the whole country's undergraduate population or the Chinese college-aged population. Third, we cannot rule out the possibility that our results are due to unmeasured variables (such as dietary intake, use of the Internet and chronic diseases) that might affect sleep quality, or to chance. Fourth, this study used a self-reported approach to collect data, including height, weight, and sleep quality, which may be subject to some reporting errors. However, the simple self-estimation of the height and weight of college students is accurate enough to be used in place of measurement [21]. Moreover, the validated and structured questionnaire has been regularly incorporated into the large epidemiologic field surveys [33]. Fifth, the methods used to access some of the questions in the questionnaire may not be accurate enough. For example, exercise intensity was measured by "how many days per week do you exercise for more than 30 minutes at a time?". There may be a lack of evidence that family and social support measures have validity and sound psychometric properties. Finally, the limitations of using PSQI to assess sleep quality studies also have been pointed out by other studies, despite its widespread use. The previous study demonstrated that the PSQI sleep parameters appeared to be more biased compared with the SelfAssessment of Sleep Survey and the Self-Assessment of Sleep Survey Split [34].

Table 4 The diagnosis of multicollinearity in univariate logistic regression analysis of sleep quality of college students

\begin{tabular}{llll}
\hline Variables & VIF & Variables & VIF \\
\hline Gender & 1.056 & Family relationship & 1.288 \\
Alcohol use & 1.062 & Communication with parents & 1.547 \\
Study pressure of this academic year & 1.032 & Satisfaction with paternal love & 2.296 \\
Days off from school(/month) & 1.210 & Satisfaction with maternal love & 2.311 \\
Self-injurious behaviors & 1.242 & Relationship with classmates & 1.240 \\
Gambling behaviors & 1.044 & Places often going with friends & \\
Exercise for more than $30 \mathrm{~min}$ (days/week) & 1.081 & & \\
\hline
\end{tabular}


Table 5 Multivariable logistic regression of factors associated with poor sleep quality

\begin{tabular}{|c|c|c|c|c|c|c|}
\hline & Estimate & SE & Wald & $P$ & OR & $95 \% \mathrm{Cl}$ \\
\hline \multicolumn{7}{|l|}{ Age } \\
\hline$\leq 20$ & -0.043 & 0.092 & 0.219 & 0.640 & 0.958 & $0.800-1.147$ \\
\hline$>20$ & & & & & 1.000 & \\
\hline \multicolumn{7}{|l|}{ Gender } \\
\hline Male & 0.004 & 0.067 & 0.004 & 0.948 & 1.004 & $0.880-1.146$ \\
\hline Female & & & & & 1.000 & \\
\hline \multicolumn{7}{|l|}{ Grade } \\
\hline Freshman & 0.421 & 0.136 & 9.645 & 0.002 & 1.523 & $1.168-1.987$ \\
\hline Sophomore & 0.283 & 0.129 & 4.798 & 0.028 & 1.327 & $1.030-1.709$ \\
\hline Junior & 0.029 & 0.123 & 0.055 & 0.815 & 1.029 & $0.809-1.308$ \\
\hline Senior and senior five & & & & & 1.000 & \\
\hline \multicolumn{7}{|l|}{ Alcohol use } \\
\hline yes & 0.491 & 0.070 & 49.346 & $<0.001$ & 1.634 & $1.425-1.874$ \\
\hline no & & & & & 1.000 & \\
\hline \multicolumn{7}{|c|}{ Study pressure of this academic year } \\
\hline no & -1.563 & 0.140 & 123.709 & $<0.001$ & 0.210 & $0.159-0.276$ \\
\hline smaller & -1.249 & 0.134 & 87.531 & $<0.001$ & 0.287 & $0.221-0.373$ \\
\hline general & -1.150 & 0.117 & 96.568 & $<0.001$ & 0.317 & $0.252-0.398$ \\
\hline larger & -0.464 & 0.120 & 14.857 & $<0.001$ & 0.629 & $0.497-0.796$ \\
\hline great & & & & & 1.000 & \\
\hline \multicolumn{7}{|c|}{ Days off from school(/month) } \\
\hline 0 & -0.673 & 0.186 & 13.091 & $<0.001$ & 0.510 & $0.354-0.735$ \\
\hline$<1$ & -0.214 & 0.204 & 1.102 & 0.294 & 0.807 & $0.541-1.204$ \\
\hline $1-2$ & -0.381 & 0.213 & 3.189 & 0.074 & 0.683 & $0.450-1.038$ \\
\hline $3-4$ & 0.044 & 0.269 & 0.027 & 0.870 & 1.045 & $0.617-1.770$ \\
\hline$\geq 5$ & & & & & 1.000 & \\
\hline \multicolumn{7}{|l|}{ Self-injurious behaviors } \\
\hline never & -0.883 & 0.268 & 10.897 & 0.001 & 0.413 & $0.245-0.698$ \\
\hline Occasionally & -0.389 & 0.302 & 1.666 & 0.197 & 0.678 & $0.375-1.224$ \\
\hline sometimes & -0.988 & 0.370 & 7.123 & 0.008 & 0.372 & $0.180-0.769$ \\
\hline often & & & & & 1.000 & \\
\hline \multicolumn{7}{|l|}{ Gambling behaviors } \\
\hline yes & 0.154 & 0.076 & 4.082 & 0.043 & 1.167 & $1.005-1.356$ \\
\hline no & & & & & 1.000 & \\
\hline \multicolumn{7}{|c|}{ Exercise for more than $30 \mathrm{~min}$ (days/week) } \\
\hline 0 & 0.210 & 0.099 & 4.512 & 0.034 & 1.234 & $1.016-1.498$ \\
\hline $1-2$ & -0.067 & 0.090 & 0.551 & 0.458 & 0.935 & $0.784-1.116$ \\
\hline $3-4$ & -0.107 & 0.104 & 1.048 & 0.306 & 0.899 & $0.732-1.103$ \\
\hline $5-7$ & & & & & 1.000 & \\
\hline \multicolumn{7}{|l|}{ Family relationship } \\
\hline Very harmonious & -0.975 & 0.278 & 12.292 & $<0.001$ & 0.377 & $0.219-0.650$ \\
\hline Harmonious & -0.748 & 0.278 & 7.225 & 0.007 & 0.473 & $0.274-0.817$ \\
\hline Neutral & -0.698 & 0.290 & 5.783 & 0.016 & 0.498 & $0.282-0.879$ \\
\hline Disharmonious & -0.191 & 0.372 & 0.264 & 0.608 & 0.826 & $0.398-1.714$ \\
\hline
\end{tabular}


Table 5 Multivariable logistic regression of factors associated with poor sleep quality (Continued)

\begin{tabular}{|c|c|c|c|c|c|c|}
\hline & Estimate & SE & Wald & $P$ & OR & $95 \% \mathrm{Cl}$ \\
\hline Highly disharmonious & & & & & 1.000 & \\
\hline \multicolumn{7}{|l|}{ Communication with parents } \\
\hline Substantial & -0.646 & 0.265 & 5.969 & 0.015 & 0.524 & $0.312-0.880$ \\
\hline Often & -0.106 & 0.148 & 0.513 & 0.474 & 0.899 & $0.672-1.203$ \\
\hline Neutral & 0.223 & 0.096 & 5.371 & 0.020 & 1.249 & $1.035-1.508$ \\
\hline Rarely & 0.077 & 0.084 & 0.827 & 0.363 & 1.080 & $0.915-1.274$ \\
\hline Never & & & & & 1.000 & \\
\hline \multicolumn{7}{|l|}{ Satisfaction with paternal love } \\
\hline Very satisfied & 0.360 & 0.228 & 2.487 & 0.115 & 1.433 & $0.916-2.240$ \\
\hline Satisfied & 0.615 & 0.202 & 9.227 & 0.002 & 1.849 & $1.244-2.749$ \\
\hline Neutral & 0.134 & 0.120 & 1.253 & 0.263 & 1.144 & $0.904-1.448$ \\
\hline Dissatisfied & -0.020 & 0.092 & 0.049 & 0.825 & 0.980 & $0.818-1.174$ \\
\hline Very dissatisfied & & & & & 1.000 & \\
\hline \multicolumn{7}{|l|}{ Satisfaction with maternal love } \\
\hline Very satisfied & -0.499 & 0.278 & 3.238 & 0.072 & 0.607 & $0.352-1.046$ \\
\hline Satisfied & -0.840 & 0.265 & 10.074 & 0.002 & 0.432 & $0.257-0.725$ \\
\hline Neutral & -0.045 & 0.151 & 0.090 & 0.765 & 0.956 & $0.712-1.284$ \\
\hline Dissatisfied & 0.016 & 0.091 & 0.030 & 0.863 & 1.016 & $0.850-1.214$ \\
\hline Very dissatisfied & & & & & 1.000 & \\
\hline \multicolumn{7}{|l|}{ Relationship with classmates } \\
\hline Very harmonious & 0.412 & 0.317 & 1.686 & 0.194 & 1.509 & $0.811-2.809$ \\
\hline Harmonious & 0.791 & 0.265 & 8.912 & 0.003 & 2.206 & $1.312-3.708$ \\
\hline Neutral & 0.531 & 0.094 & 31.805 & $<0.001$ & 1.700 & $1.414-2.045$ \\
\hline Disharmonious & 0.107 & 0.076 & 1.972 & 0.160 & 1.113 & $0.958-1.293$ \\
\hline Highly disharmonious & & & & & 1.000 & \\
\hline \multicolumn{7}{|l|}{ Places often going with friends } \\
\hline Gymnasium & -0.261 & 0.079 & 10.914 & 0.001 & 0.770 & $0.659-0.899$ \\
\hline Bar/Karaoke hall/Song and dance hall & 0.080 & 0.092 & 0.768 & 0.381 & 1.084 & $0.905-1.297$ \\
\hline Billiard hall & -0.258 & 0.148 & 3.056 & 0.080 & 0.773 & $0.579-1.032$ \\
\hline Internet cafes & -0.259 & 0.110 & 5.502 & 0.019 & 0.772 & $0.622-0.958$ \\
\hline Other & & & & & 1.000 & \\
\hline
\end{tabular}

Note: $d f=1$

\section{Conclusions}

In sum, our results could still serve as an important implication to identify the factors that affect poor sleep and to develop prevention strategies for college students to promote healthy sleeping habits, which should cover factors such as study pressure, family and social support, mental health, and physical exercise. It is worth noting that college students must be made aware of the consequences of inadequate sleep quality and that risk factors could be improved if students tried to change their behavior and subjective consciousness.

\section{Supplementary information}

Supplementary information accompanies this paper at https://doi.org/10. 1186/s12955-020-01465-2.

Additional file 1 Appendix 1. The assignment of the variables included in the logistic regression. Appendix 2. PSQI component scores and total scores $(\mathrm{M} \pm \mathrm{SD})$ in all participants and by gender.

Abbreviations

PSQI: Pittsburgh Sleep Quality Index; VIF: Variance inflation factor; BMI: Body mass index; OR: Odds ratios; Cl: Confidence intervals; SD: Standard deviation

\section{Acknowledgments}

The authors wish to acknowledge all the study participants. 


\section{Authors' contributions}

Conception and design: CG, WJ. Collection and assembly of data: YY, WB, BZ, $R X, X Y, W X, M H, W Q, W Y$. Data analysis and interpretation: $Y Y, W B, B Z, R X, X Y$, WX, MH, WQ, WY. Writing: YY. All authors read and approved the final manuscript.

\section{Funding}

This research did not receive any specific grant from funding agencies in the public, commercial, or not-for-profit sectors.

\section{Availability of data and materials}

The datasets used and/or analyzed during the current study are available from the corresponding author on reasonable request.

\section{Ethics approval and consent to participate}

All participants provided written informed consent prior to participating in the survey. This study was approved by the Survey and Behavioral Ethics Committee of the School of Public Health, Jilin University.

\section{Consent for publication}

Publication consent was obtained from all individual participants included in the study.

\section{Competing interests}

The authors have no conflicts of interest in conducting this study or preparing the manuscript.

\section{Author details}

'Department of Epidemiology and Biostatistics, School of Public Health, Jilin University, 1163 Xinmin Street, Changchun 130021, Jilin province, China. ${ }^{2}$ Department of Social Medicine and Health Management, School of Public Health, Jilin University, Changchun 130021, China.

Received: 28 May 2019 Accepted: 26 June 2020

Published online: 01 July 2020

\section{References}

1. Sleep and sleep disorders. Centers for Disease Control and Prevention. https://www.cdc.gov/sleep/index.html. Accessed March 12, 2019.

2. Hinz A, Glaesmer H, Brahler E, Loffler M, Engel C, Enzenbach C, Hegerl U, Sander C. Sleep quality in the general population: psychometric properties of the Pittsburgh sleep quality index, derived from a German community sample of 9284 people. Sleep Med. 2017;30:57-63.

3. Wong WS, Fielding R. Prevalence of insomnia among Chinese adults in Hong Kong: a population-based study. J Sleep Res. 2011;20:117-26.

4. Pilcher JJ, Ginter DR, Sadowsky B. Sleep quality versus sleep quantity: relationships between sleep and measures of health, well-being and sleepiness in college students. J Psychosom Res. 1997:42:583-96.

5. Carshdon MA, Davis SS. Sleep-wake patterns in the high school-to-college transition: preliminary data. Sleep Res. 1989.

6. Tsui YY, Wing YK. A study on the sleep patterns and problems of university business students in Hong Kong. J Am Coll Heal. 2009:58:167-76.

7. Lund $H G$, Reider BD, Whiting AB, Prichard JR. Sleep patterns and predictors of disturbed sleep in a large population of college students. J Adolesc Health. 2010:46:124-32.

8. Li L, Wang YY, Wang SB, Zhang L, Li L, Xu DD, Ng CH, Ungvari GS, Cui X, Liu ZM, et al. Prevalence of sleep disturbances in Chinese university students: a comprehensive meta-analysis. J Sleep Res. 2018;27:e12648.

9. Li L, Wang YY, Wang SB, Li L, Lu L, Ng CH, Ungvari GS, Chiu HFK, Hou CL, Jia FJ, Xiang YT. Sleep duration and sleep patterns in Chinese University students: a comprehensive meta-analysis. J Clin Sleep Med. 2017:13:1153-62.

10. Suen LK, Hon KL, Tam WW. Association between sleep behavior and sleeprelated factors among university students in Hong Kong. Chronobiol Int. 2008:25:760-75

11. Feng GS, Chen JW. Yang XZ: [study on the status and quality of sleeprelated influencing factors in medical college students]. Zhonghua Liu Xing Bing Xue Za Zhi. 2005;26:328-31.

12. Mander BA, Winer JR, Walker MP. Sleep and Human Aging. Neuron. 2017:94:19.

13. Zhang HS, Li Y, Mo HY, Qiu DX, Zhao J, Luo JL, Lin WQ, Wang JJ, Wang PX. A community-based cross-sectional study of sleep quality in middle-aged and older adults. Qual Life Res. 2017;26:923-33.
14. Wang S, Wu Y, Ungvari GS, Ng CH, Forester BP, Gatchel JR, Chiu HFK, Kou C, Fu Y, Qi Y, et al. Sleep duration and its association with demographics, lifestyle factors, poor mental health and chronic diseases in older Chinese adults. Psychiatry Res. 2017;257:212-8.

15. Morahan-Martin J, Schumacher P. Incidence and correlates of pathological internet use among college students. Comput Hum Behav. 2000;16:13-29.

16. Choi K, Son H, Park M, Han J, Kim K, Lee B, Gwak H. Internet overuse and excessive daytime sleepiness in adolescents. Psychiatry Clin Neurosci. 2009;63:455-62.

17. Chen J, Wu Y, Yi H, Li Z, Eshita Y, Qin P, Chen L, Sun J. The impact of academic stress on medical students attending college in the Inner Mongolia area of China. Open J Prev Med. 2013;3:149-54.

18. Buysse DJ, Reynolds CF 3rd, Monk TH, Berman SR, Kupfer DJ. The Pittsburgh sleep quality index: a new instrument for psychiatric practice and research. Psychiatry Res. 1989;28:193-213.

19. Tsai PS, Wang SY, Wang MY, Su CT, Yang TT, Huang CJ, Fang SC. Psychometric evaluation of the Chinese version of the Pittsburgh sleep quality index (CPSQI) in primary insomnia and control subjects. Qual Life Res. 2005;14:1943-52.

20. Vargas PA, Flores M, Robles E. Sleep quality and body mass index in college students: the role of sleep disturbances. J Am Coll Heal. 2014;62:534-41.

21. Imrhan S. VICTORINEIMRHAN, CURTISHART: can self-estimates of body weight and height be used in place of measurements for college students? Ergonomics. 1996;39:1445-53.

22. Kang JH, Chen SC: Effects of an irregular bedtime schedule on sleep quality, daytime sleepiness, and fatigue among university students in Taiwan. BMC Public Health 2009, 9:248.

23. Lemma S, Gelaye B, Berhane Y, Worku A, Williams MA. Sleep quality and its psychological correlates among university students in Ethiopia: a crosssectional study. Bmc Psychiatry. 2012;12:237.

24. Cheng SH, Shih CC, Lee IH, Hou YW, Chen KC, Chen KT, Yang YK, Yang YC. A study on the sleep quality of incoming university students. Psychiatry Res. 2012;197:270-4.

25. Wang Y, Li Y, Liu X, Liu R, Mao Z, Tu R, Zhang H, Zhang X, Qian X, Jiang J, et al. Gender-specific prevalence of poor sleep quality and related factors in a Chinese rural population: the Henan rural cohort study. Sleep Med. 2019; 54:134-41.

26. Gildner TE, Liebert MA, Kowal P, Chatterji S, Josh Snodgrass J. Sleep duration, sleep quality, and obesity risk among older adults from six middleincome countries: findings from the study on global AGEing and adult health (SAGE). Am J Hum Biol. 2014;26:803-12.

27. Spiegel K, Leproult R, Van Cauter E. Impact of sleep debt on metabolic and endocrine function. Lancet. 1999:354:1435-9.

28. Rahe C, Czira ME, Teismann H, Berger K. Associations between poor sleep quality and different measures of obesity. Sleep Med. 2015;16:1225-8.

29. Grandner MA, Patel NP, Gehrman PR, Xie D, Sha D, Weaver T, Gooneratne N. Who gets the best sleep? Ethnic and socioeconomic factors related to sleep complaints. Sleep Med. 2010;11:470-8.

30. Tang J, Liao Y, Kelly BC, Xie L, Xiang YT, Qi C, Pan C, Hao W, Liu T, Zhang F, Chen X. Gender and regional differences in sleep quality and insomnia: a general population-based study in Hunan Province of China. Sci Rep. 2017;7:43690.

31. Yao KW, Yu S, Cheng SP, Chen IJ. Relationships between personal, depression and social network factors and sleep quality in communitydwelling older adults. J Nurs Res. 2008;16:131-9.

32. Vandekerckhove M, Cluydts R. The emotional brain and sleep: an intimate relationship. Sleep Med Rev. 2010;14:219-26.

33. Roberts RE, Shema SJ, Kaplan GA, Strawbridge WJ. Sleep complaints and depression in an aging cohort: a prospective perspective. Am J Psychiatry. 2000;157:81-8.

34. Dietch JR, Sethi K, Slavish DC, Taylor DJ. Validity of two retrospective questionnaire versions of the consensus sleep diary: the whole week and split week self-assessment of sleep surveys. Sleep Med. 2019;64.

\section{Publisher's Note}

Springer Nature remains neutral with regard to jurisdictional claims in published maps and institutional affiliations. 